\title{
A cluster of culture positive gonococcal infections but with false negative $c p p B$ gene based PCR
}

\author{
G Lum, K Freeman, N L Nguyen, E A Limnios, S N Tabrizi, I Carter, I W Chambers, D M Whiley, \\ T P Sloots, S M Garland, J W Tapsall
}

Objectives: To describe the prevalence and characteristics of isolates of Neisseria gonorrhoeae grown from urine samples that produced negative results with nucleic acid amplification assays (NAA) targeting the $c p p B$ gene.

Methods: An initial cluster of culture positive, but $\operatorname{sp} B$ gene based NAA negative, gonococcal infections was recognised. Urine samples and suspensions of gonococci isolated over 9 months in the Northern Territory of Australia were examined using $с р p B$ gene based and other non-сppB gene based NAA. The gonococcal isolates were phenotyped by determining the auxotype/serovar (A/S) class and genotyped by pulsed field gel electrophoresis (PFGE).

Results: 14 (9.8\%) of 143 gonococci isolated were of $A / S$ class Pro ${ }^{-1}$ Brpyut, indistinguishable on PFGE and negative in сppB gene based, but not other, NAA.

Conclusions: This cluster represents a temporal and geographic expansion of a gonococcal subtype lacking the $\mathrm{cpp} B$ gene with consequent loss of sensitivity of NAA dependent on amplification of this target. Gonococci lacking the $c p p B$ gene have in the past been more commonly associated with the $\mathrm{PAU}^{-} / \mathrm{PCU}^{-}$auxotype, a gonococcal subtype hitherto infrequently encountered in Australia. NAA based on the $с p p B$ gene as a target may produce false positive as well as false negative NAA. This suggests that unless there is continuing comparison with culture to show their utility, срpB gene based NAA should be regarded as suboptimal for use either as a diagnostic or supplemental assay for diagnosis of gonorrhoea, and NAA with alternative amplification targets should be substituted.

A ssays for the detection of Neisseria gonorrhoeae using sequences found in the $с p p B$ gene have been used over a considerable period. The $\operatorname{cpp} B$ gene is located on a $4.2 \mathrm{~kb}$ cryptic plasmid in $N$ gonorrhoeae which, in early studies, was found to be widely distributed. ${ }^{1}$ A non-amplified DNA probe test based on its detection was developed ${ }^{2}$ and released commercially, but the sensitivity of this test was about $90 \%$. Notably, gonococci of the proline-arginine-uracil/ proline-citrulline-uracil ( $\left.\mathrm{PAU}^{-} / \mathrm{PCU}\right)$ auxotype were, in particular, shown to lack the cryptic plasmid and this association became firmly established following studies in Canada showing a sustained temporal expansion of this gonococcal subtype.

Subsequently, a number of "in house" nucleic acid amplification assays (NAA) were developed using published sequences of the $\operatorname{cppB}$ gene. ${ }^{4-6}$ The considerable recombination occurring within the plasmid DNA also saw some incomplete $с p p B$ gene sequences appear in the chromosome, ${ }^{7}$ but in low copy numbers. Thus, decreased sensitivity arising from absent, altered, or low copy numbers of the chosen sequence, is reported with this $c p p B$ gene based NAA. ${ }^{8} 9$

We describe here the detection of a cluster of cases which gave negative reactions on urine samples examined with $с p p B$ gene based NAA but which yielded non-PAU ${ }^{-} / \mathrm{PCU}^{-}$ gonococci when the same sample was cultured. The implications for continuing use of $c p p B$ gene based NAA for either primary or supplemental confirmation of gonococcal infection are discussed.

\section{MATERIALS AND METHODS}

As part of an expanded programme of gonococcal susceptibility surveillance in the Northern Territory of Australia, all urine samples submitted to the Royal Darwin Hospital for testing by a $\angle p p B$ gene based $\mathrm{NAA}^{6}$ were also cultured to obtain isolates of $N$ gonorrhoeae. In the second half of 2002, eight urine samples from six men and two women were negative on the $с p p B$ gene based NAA, while gonococci were cultured from the same sample. The urine samples were stored and re-assayed using the same NAA in a different laboratory.

All the isolates were confirmed as $N$ gonorrhoeae by standard procedures and referred to the coordinating laboratory for the Australian Gonococcal Surveillance Programme (AGSP) in Sydney. Here their extended phenotype was ascertained by determining the auxotype; serovar from agglutination patterns observed with 14 monoclonal antibodies (Boule, Huddinge Sweden) to outer membrane protein epitopes; and pattern of antibiotic susceptibility to penicillin, ceftriaxone, ciprofloxacin, spectinomycin, and tetracycline obtained using the test methods of the AGSP. The Sydney laboratory also examined the auxotype and antibiotic susceptibility patterns (partial phenotype) of all 143 isolates routinely referred there from all sites in the Northern Territory in the period I June 2002 to 31 March 2003 as part of the susceptibility surveillance programme of the AGSP. The full extended phenotype of those gonococci with a partial phenotype similar to that of the "outbreak" strains and another $58(40 \%)$ randomly selected from the 143 referred Northern Territory gonococci were also determined.

Genomic DNA prepared from gonococci exhibiting the "cluster" phenotype and another six "background" strains (that is, different phenotypes) was digested separately with BglII and SpeI and examined by pulsed field gel electrophoresis (PFGE) on a CHEF-DR III (Biorad, CA, USA) apparatus using methods previously described. ${ }^{10}$

Suspensions of all 143 Darwin isolates were re-examined with two $c p p B$ gene based NAA, ${ }^{611}$ the Cobas-Amplicor NAA (Roche Diagnostic Systems, NJ, USA) and a real time opa

Abbreviations: AGSP, Australian Gonococcal Surveillance Programme; A/S, auxotype/serovar; NAA, nucleic acid amplification assays; PAU/PCU, proline-arginine-uracil/proline-citrulline-uracil;

PCR, polymerase chain reaction; PFGE, pulsed field gel electrophoresis 
gene based NAA. ${ }^{12}$ In addition, suspensions of those strains negative in the $c p p B$ gene based NAA were examined by the BD Probe-Tec (Becton Dickenson, MD, USA) and LCX (Abbott Laboratories, IL, USA) NAAs.

\section{RESULTS}

A total of 14 of the $143(9.8 \%)$ gonococcal isolates from Darwin, including the eight original isolates, were nonreactive in the $\angle P p B$ gene based NAAs, but positive in three commercial and one "in house" NAA with amplification targets other than the $\angle p p B$ gene. Repeat NAAs of the original urine samples that initially gave negative $c p p B$ based NAA results remained negative with a second $с p p B$ gene based test. The additional six non-reactive gonococci found in the retrospective analysis were grown from specimens referred from locations other than the Darwin clinic and no NAAs were performed. Suspensions of the remaining 129 gonococci were positive in all NAAs used.

The 14 gonococci negative in $\operatorname{cppB}$ gene based assays were phenotypically and genotypically indistinguishable, but distinct from the other 129 gonococci isolated from the same source. All were of the IB serogroup and of the Brpyut serovar. All were proline auxotypes, but had no requirement for arginine/citrulline or uracil. Sixteen different auxotype/ serovar classes were present in the 58 strains positive in $с p p B$ gene based NAA and whose extended phenotype was determined and, specifically, none was Pro ${ }^{-}$/Brpyut.

\section{DISCUSSION}

In this report we noted discordance between $c p p B$ gene based NAA and culture results directly in clinical samples and this was only detected because of a continuing need to derive isolate based susceptibility test data. This fortuitous finding extends observations on the lack of sensitivity of $\operatorname{cp} B$ gene based PCR. Palmer et $a l^{13}$ observed a low sensitivity of $\operatorname{cppB}$ gene based NAA when using suspensions of specially selected laboratory based cultures and Bruisten et al ${ }^{9}$ found the $\operatorname{cpp} B$ target absent in 26 of $448(5.8 \%)$ gonococci retested by NAA in a laboratory evaluation project. While the sensitivity of the assay or natural inhibitors of PCR present in urine may on occasion account for some negative NAA results, this does not seem to be the reason for the negative results observed here. Urine samples negative with $с p p B$ gene based NAA were also negative when retested using the stored specimens as were suspensions of the gonococci cultured from those samples. However, NAA with different targets to the $с p p B$ gene gave positive results with these urine samples and isolate suspensions.

Another relevant finding was that the gonococci testing negative in the $c p p B$ gene based NAA were of the Pro ${ }^{-}$but not $\mathrm{PAU}^{-} / \mathrm{PCU}^{-}$auxotype. The $\mathrm{PAU}^{-} / \mathrm{PCU}^{-}$auxotype has previously been linked to the absence of the cryptic plasmid. ${ }^{313}$ This study confirms earlier studies indicating that a diversity of gonococcal auxotypes may be associated with a plasmid free state $^{14}$ and that the proportion of gonococci exhibiting this characteristic may vary substantially over time and place. $^{314}$ At the time of this study, these gonococci were seemingly confined to the Northern Territory. All 300 gonococci from elsewhere in Australia examined in a gene based NAA gave a positive result. ${ }^{11}$ However, subsequent to the completion of this study, two further Pro ${ }^{-}$/Brpyut gonococci were isolated in Sydney from urethral infections acquired outside Australia. Urine samples from these patients were negative with a $c p p B$ gene based NAA but both the urine and suspensions of the isolates were positive in non- $с p p B$ gene based assays, suggesting a wider distribution of this $с p p B$ gene negative gonococcal subtype.

Palmer et $a l^{13}$ also noted the presence of the $\operatorname{cppB}$ gene sequence in other Neisseria organisms that led to false positive results with NAA based on amplification of this target, although the prevalence of these strains may also vary with the population studied. These findings, together with those of Bruiston et $a l^{9}$ and the data reported here, suggest that other NAA are preferable to the problematic $\operatorname{cpp} B$ gene based assays. Their continued use, either as a diagnostic or supplemental assay for diagnosis of gonorrhoea, should be contingent upon on continuing assessment of the proportion of gonococci lacking this target site by means of evaluations which directly assess both culture and NAA performance.

Alternatives to the $\angle p p B$ gene based assay have been proposed including NAA targeting the opa gene ${ }^{12}$ and the porA pseudogene. ${ }^{8}$ The latter NAA is now in use in the Northern Territory. Earlier studies comparing the $\operatorname{cp} p B$ gene based assay with the Amplicor test reported a high false positive rate for the Amplicor NAA, ${ }^{511}$ leading to a recommendation that samples positive with the Amplicor NAA require additional investigation. This current study suggests that an additional explanation for the discrepant results may be that some of these reportedly false positive results in the Amplicor NAA may have been true positives, but were not confirmed by a false negative $c p p B$ gene based NAA. Another study from Victoria found a single instance of a culture positive gonococcal infection where a $с p p B$ gene based NAA was negative. ${ }^{15}$ The isolate was not examined further but there was concordance between culture and NAA tests in 39 other instances. ${ }^{6}$ It is, however, accepted that the Amplicor NAA gives a rate of false positive NAA for gonorrhoea that requires confirmation. ${ }^{16}$ Further, some other commercial NAA for gonorrhoea were withdrawn from distribution when wider use in diagnostic settings revealed problems not detected in pre-release evaluations. While some newer NAA have been described and/or marketed, ${ }^{8}{ }^{12}$ recent experience now suggests it would be prudent to continue to monitor their longer term performance and particularly their applications in extragenital tract gonococcal infection.

\section{ACKNOWLEDGEMENTS}

We thank John Davies for helpful discussions, Kym Payne, and Sally Dubedat for performing some assays, and Tiffany Hogan, Sanghamithra Ray, and Caterina Patsianis for technical assistance.

\section{CONTRIBUTORS}

KF and GL collected and tested samples in Darwin; IWC tested samples in Sydney; IC, SNT, SG, DW, and TS performed and supervised various NAA in Melbourne and Brisbane; EAL and NLN performed the phenotypic and genotypic analyses; EAL and JWT analysed data and coordinated the project; all contributed to discussions on the text which was written by JWT.

\section{Authors' affiliations \\ G Lum, K Freeman, Department of Microbiology, Royal Darwin Hospital, Casuarina, Northern Territory, Australia \\ N L Nguyen, E A Limnios, I Carter, J W Tapsall, Microbiology Department, South Eastern Area Laboratory Services, Sydney, New South Wales, Australia \\ S N Tabrizi, S M Garland, Department of Microbiology, Royal Women's Hospital, Melbourne, Victoria, Australia \\ I W Chambers, Douglass Hanly Moir Pathology, Ryde, New South Wales, Australia \\ D M Whiley, T P Sloots, Clinical Virology Research Unit, Sir Albert Sakzewski Virus Research Centre, Royal Children's Hospital and Health Service District Brisbane, Queensland, Australia \\ There are no competing interests.}

Correspondence to: J W Tapsall, Department of Microbiology, The Prince of Wales Hospital, Randwick, New South Wales, Australia 2031; j.tapsall@unsw.edu.au

Accepted for publication 2 December 2004 


\section{REFERENCES}

1 Roberts $M$, Piot P, Falkow S. The ecology of gonococcal plasmids. J Gen Microbiol 1979;1 14:491-4.

2 Totten PA, Holmes KK, Handsfield HH, et al. DNA hybridization technique for the detection of Neisseria gonorrhoeae in men with urethritis. $J$ Infect Dis 1983;148:462-71.

3 Dillon JR, Bygdeman SM, Sandstrom EG. Serological ecology of Neisseria gonorrhoeae (PPNG and non-PPNG) strains: Canadian perspective. Genitourin Med 1987;63:160-8.

4 Tabrizi SN, Paterson B, Fairley K, et al. A self-administered technique for the detection of sexually transmitted diseases in remote communities. J Infect Dis 1997; 176:289-92.

5 Farrell DJ. Evaluation of Amplicor Neisseria gonorrhoeae PCR using срpB nested PCR and 16S rRNA PCR. J Clin Microbiol 1999;37:386-90.

6 Whiley DM, LeCornec GM, Mackay IM, et al. A real-time PCR assay for the detection of Neisseria gonorrhoeae by LightCycler. Diagn Microbiol Infect Dis 2002;167:231-7.

7 Hagblom P, Korch C, Jonsson A-B, et al. Intragenic variation by site-specific recombination in the cryptic plasmid of Neisseria gonorrhoeae. J Bacteriol 1986;167:231-7.

8 Whiley DM, Buda PJ, Bayliss J, et al. A new confirmatory Neisseria gonorrhoeae real-time PCR assay targeting the porA pseudogene. Eur I Clin Microbiol Infect Dis 2004;23:705-10.
9 Bruisten SM, Noordhoek GT, van den Brule, et al. Multicentre validation of the cppB gene as a PCR target for detection of Neisseria gonorrhoeae. J Clin Microbiol 2004;42:4332-4.

10 Poh CL, Loh GL, Tapsall JW. Resolution of clonal subgroups among Neisseria gonorrhoeae IB-2 and IB-6 serovars by pulsed-field gel electrophoresis. Genitourin Med 1995;71:145-9.

11 Tabrizi SN, Chen S, Cohenford MA, et al. Evaluation of real time polymerase chain reaction assays for confirmation of Neisseria gonorrhoeae in clinical samples tested positive in the Roche Cobas Amplicor assay. Sex Transm Infect 2004:80:68-71.

12 Tabrizi SN, Chen S, Tapsall J, et al. Evaluation of opa-based real time PCR for detection of N gonorrhoeae. Sex Transm Dis 2005;32:199-202.

13 Palmer HM, Mallinson H, Wood RL, et al. Evaluation of the specificities of five DNA amplification methods for the detection of Neisseria gonorrhoeae. J Clin Microbiol 2003:41:835-7.

14 Abeck D, Johnson AP, Alexander FE, et al. Plasmid content and protein I serovar of non-penicillinase-producing gonococci isolated in Munich. Epidemiol Infect 1988;100:345-9.

15 Leslie DE, Azzato F, Ryan N, et al. An assessment of the Roche Amplicor Chlamydia trachomatis/Neisseria gonorrhoeae multiplex PCR assay in routine diagnostic use on a variety of specimen types. Commun Dis Intelligence 2003;27:373-79.

16 Centers for Disease Control and Prevention. Screening tests to detect Chlamydia trachomomatis and Neisseria gonorrhoeae-2002. Morb Mort Wkly Rep 2002;51:1-38. 